\title{
Tactics employed by healthcare providers in Denmark to determine the vaccination needs of asylum-seeking children: a qualitative study
}

\author{
Cathrine S. Nakken ${ }^{1}$, Marie Norredam ${ }^{1,2}$ and Morten Skovdal ${ }^{1 *}$ (1)
}

\begin{abstract}
Background: Many asylum-seekers to Denmark come from war-torn countries where conflict and insufficient health care infrastructures disrupt vaccine programmes and result in very few children and their families presenting documentation of vaccinations on their arrival in asylum-centers. There is a need to explore how healthcare providers, in the absence of vaccine documentation, determine the vaccination needs of newly arrived refugee children.

Methods: To explore the tactics employed by healthcare professionals who screen and vaccinate asylum-seeking children in Denmark, we conducted semi-structured interviews between December 2015 and January 2016 with six healthcare professionals, including three doctors and three public health nurses. The interviews were digitally recorded, transcribed and subjected to a thematic network analysis.

Results: The analysis revealed that healthcare providers adopt a number of tactics to ascertain children's immunization needs. They ask into the children's vaccination history through the use of qualified interpreters; consult WHO lists of immunization programmes worldwide; draw on tacit knowledge about country vaccination programmes; consider the background of parents; err on the side of caution and revaccinate.

Conclusions: This is one of the first studies to demonstrate the tactics employed by healthcare providers to ascertain the immunization needs of asylum-seeking children in a western receiving country. The findings suggest a need for clear guidance at a national level on how to determine the vaccination needs of asylum-seeking children, and an international effort to secure reliable immunization documentation for migrant populations, for example through virtual immunization records.
\end{abstract}

Keywords: Refugee children, Asylum-seeking children, Immunization, Vaccination, Healthcare workers, Tactics, Denmark

\section{Background}

European countries have in recent years experienced a large influx of asylum-seekers as a result of conflicts and civil unrest in parts of North Africa, the Middle East and Central Asia. According to the European Commission, over 1.3 million asylum applicants were registered

\footnotetext{
* Correspondence: m.skovdal@gmail.com

${ }^{1}$ Danish Research Center for Migration, Ethnicity and Health, Section for Health Services, Research, Department of Public Health, University of Copenhagen, Øster Farimagsgade 5, 1353 København K, Denmark Full list of author information is available at the end of the article
}

in Europe in 2015. An estimated 30\% of all asylumseekers are children, of whom nearly a quarter are unaccompanied [1]. In Denmark alone, a little more than 21,000 refugees applied for asylum in 2015, an increase of $44 \%$ compared to the previous year [2]. Although the number of asylum-seekers has plummeted in recent years, the sudden influx of migrants and refugees in the run up to 2015 offers a unique opportunity to critically examine the preparedness of European health services in responding to the health needs of asylum-seekers. One health response pertains to vaccinations. The World

(c) The Author(s). 2018 Open Access This article is distributed under the terms of the Creative Commons Attribution 4.0 International License (http://creativecommons.org/licenses/by/4.0/), which permits unrestricted use, distribution, and reproduction in any medium, provided you give appropriate credit to the original author(s) and the source, provide a link to the Creative Commons license, and indicate if changes were made. The Creative Commons Public Domain Dedication waiver (http://creativecommons.org/publicdomain/zero/1.0/) applies to the data made available in this article, unless otherwise stated. 
Health Organization (WHO) [3] states that asylumseekers and migrants should be vaccinated as soon as possible according to the vaccination program of the country in which they intend to settle in. Vaccination initiatives targeting child asylum-seekers are important because young children are at particular risk of not having completed their vaccination course because of war and conflict-related interruptions to the vaccination programmes in their home countries as well as lack of access to immunization programs while on the run/migrating [4].

All asylum seekers to Denmark are upon their arrival accommodated in a reception asylum center north of Copenhagen, and later referred to other asylum centers. It is the reception asylum center, which is run by Red Cross Denmark that is primarily responsible for the vaccination of asylum-seeking children. Within 10 days of arrival, a voluntary health assessment is offered at the health clinic of the reception asylum center. Children $(<18$ years of age) are assessed by a nurse and a doctor separately. In accordance with current guidelines of the National Board of Health [5], asylum-seekers should be vaccinated according to the national routine immunization schedule. However, asylum-seeking families only very rarely carry documentation of their immunization history [6, 7], and rarely recall what vaccines their children have received in the past [8]. Against this background, we explore how healthcare providers determine the vaccination needs of asylum-seeking children.

To do this we frame the actions of healthcare providers as 'tactics', taking inspiration from de Certeau's [9] notions of 'strategies and tactics'. Strategies refer to the direction offered by people or organizations in positions of power, such as the State. This may include funding cuts, policy changes, national and international guidelines, or the absence thereof. Tactics on the other hand may refer to the everyday acts and occurrences that healthcare providers adapt in order to exhume a bit of control, or make do, in a setting deemed constraining. By drawing on de Certeau's notion of 'tactics', we can disentangle the bundle of 'doings' that healthcare providers - in the context of broader political, cultural and economic forces - adapt in their everyday routines in order to cooperate, resist or deal with factors constraining their ability to determine the vaccination needs of asylum-seeking children.

\section{Methods}

To understand how healthcare professionals ascertain the immunization needs of asylum-seeking children we employed an exploratory qualitative interview study design. We opted for an interview study design because it allowed us to flexibly and exploratory examine their experiences, perspectives and accounts of how they determined the vaccination needs of asylum-seeking children. The study was registered with the Danish Data Protection agency and followed their ethical guidelines. Informed consent was obtained from all participants, who in turn were assured confidentiality.

\section{Study setting and participants}

At the start of 2017, there were 45 asylum centers in Denmark run by the Red Cross or different municipalities. These include a reception center, two departure centers, eight children centers, and one 'special care' center [10]. In 2015, we invited three public health nurses and three medical doctors (age 45-65) working at two Red Cross asylum centers, including the reception center, to participate in the study. The participants worked at centers in the Zealand area of Denmark and were identified via a gatekeeper who was an employee stakeholder. All those invited to participate in the study agreed to do so. As per our inclusion criteria, the healthcare providers, as part of their day-to-day routine of offering health services to asylum seekers, screened and vaccinated asylum-seeking children arriving in Denmark. Apart from one participant who had only recently been employed (but who had broad experience within the same field in the public sector), all had extensive prior experience of working for the Red Cross. None of the participants were previously known to the researcher. We made a conscious decision of only recruiting six healthcare workers, as only a very small number of healthcare providers routinely screen and vaccinate asylum-seeking children in Denmark. If we recruited many more, it would be difficult to ensure anonymity. Our six participants effectively make up a significant and representative proportion of healthcare workers routinely vaccinating asylum-seeking children.

\section{Data collection and analysis}

The interviews took place during the months of December 2015 and January 2016 and were conducted faceto-face at the two asylum centers. The interviews were structured by a topic guide collaboratively developed by the authors. We devised questions by drawing on thematic categories presented by Mulrow et al. [11] and Ozbolt and Faan [12] who highlight materials (e.g., policies and guidelines), competences (e.g., understanding of patient's situation) and meanings (e.g., ethics) as core elements entering into clinical decisions. We ended up with 14 questions, covering topics such as information availability, cultural and language barriers to communication, resource availability, the use of decision making tools, time availability and age-based access concerns'.

The interviews lasted an average of $45 \mathrm{~min}$ and were conducted by $\mathrm{CN}$ (a native Norwegian speaker) in a mix of Norwegian-Danish. Due to the similarities between 
Norwegian and Danish, this mixing of the two languages did not appear to impact the flow of the interviews.

$\mathrm{CN}$ subsequently translated and transcribed the interviews into English and used the 'table method' for coding text segments within the transcripts [13]. This involved, firstly, transferring text segments into word document tables, and secondly, printing, cutting out and placing the codes, which make up basic themes, on an actual table for an exploration of networked themes [13, 14]. This involved $\mathrm{CN}$ and MS working together to cluster the 12 emerging basic themes into six more interpretive organizing themes. This process of cross case analysis, enabled us to move beyond description of individuals' accounts and their individualized personal experiences, and instead map out and condense some of the more prevalent experiences and perceptions as reported by the informants. As not all the basic and organizing themes are of relevance to this article, and because the strategies devised by our participants to determine the vaccination needs of asylum-seeking children emerged as a significant finding, we proceeded with a secondary and more interpretive interrogation of our emerging themes, aided by our theoretical framework. This process led to a new thematic network, with nine of our basic themes contributing to five new global themes (which make up the structure of our results) and one global theme (see Table 1).

\section{Results}

Asylum-seeking children presenting to Red Cross Asylum centres are subject to routine statutory health screening. This involves, first, an appointment with a public health nurse, who talks to the child and accompanying adults about their medical history. The nurse documents everything. After seeing the public health nurse, the children will be referred to a doctor for further examinations and vaccinations as necessary. The doctors have the final say in determining whether a child needs vaccinations. At one center, it was only the doctors who vaccinated, while at another center, the public health nurses also administered vaccinations. Both the public health nurses and the doctors expressed difficulty in ascertaining the vaccination needs of asylum-seeking children, stating that almost no one came with documentation of their vaccinations on arrival, relying on their memory and self-reported accounts of vaccinations. Elsewhere we have reported that nearly a third of asylum-seeking children and adolescents in Denmark were in need of further vaccinations [15]. We now present findings on some of the tactics these healthcare professionals adopted - in the absence of documentation - to decide what children to vaccinate, and allude to some of the challenges of these tactics.

\section{Tactic 1: asking into their vaccination history through the use of qualified interpreters}

They all stated that the use of interpreters played an important role in enabling the communication between themselves, the children and their families. All agreed that it was important to have access to an interpreter who could be physically present and who was knowledgeable about the medical field. One doctor said it was expected that the interpreters would know medical expressions and vaccine names, and not ask the families if their children had received the 'blue looking vaccination' against the disease that 'gives red dots' and so on.

"Well, it is expected that the interpreters know the terms and can interpret sufficiently. And it shouldn't be at the level where they ask 'have you gotten the red vaccine?' or 'the blue medicine' or... that's not good enough... they are supposed to know the terms and expressions. And I presume that the parents get the information on what it is we are doing, like "now he is vaccinated against...' and such, right? I presume that." -Doctor, Red Cross.

Table 1 Thematic network: from codes to global theme

\begin{tabular}{lll}
\hline Codes and basic themes & Organising themes & Global theme \\
\hline - Communication obstacles & Tactic 1: Asking into their vaccination history & Tactics employed by healthcare providers \\
- Feelings and experiences around & through the use of qualified interpreters & to determine the vaccination needs of \\
the use interpreters & Tactic 2: Consulting WHO lists of immunization & programmes worldwide \\
- Use of information 'tools' & Tactic 3: Drawing on tacit knowledge about \\
- Lack of vaccination documentation & country vaccination programmes \\
- Limited time available for screening & \\
and vaccinations & Tactic 4: Considering the background of parents \\
- Cultural differences and barriers & \\
- Information given from parents & Tactic 5: Err on the side of caution and revaccinate \\
\hline
\end{tabular}


Some of the public health nurses stated that they preferred interpreters to be physically present, but that they are now expected to cut costs and use phone interpreters. This implied different challenges, for example, if the families came late and the interpreter was scheduled for other calls, there would not be time to assess their vaccination needs. There could also be a lot of noise when families with many children were in the office, which made it difficult to hear the interpreter speaking on the phone. These challenges were often compounded, if the families spoke local dialects that the interpreters were not familiar with. A doctor also mentioned that it was also quite challenging to translate the vaccination documentation over the phone, since he, or the family, could not read and pronounce the words correctly.

Nonetheless, all of the healthcare professionals mentioned that most of the interpreters they had encountered did a professional and important job as their spokespersons at the asylum centers. A public health nurse mentioned that they occasionally encountered interpreters of sub-standard; however, she now had the experience to be able to deal with such challenges.

"The interpreters are very professional. I think the ones we work with are good ones. Of course, we have had interpreters who were not good, but then we do something about it. So I feel it's working out, and I also begin to understand a bit of what they say, because after a while of listening to a language one learns to hear if they say something that sounds familiar or something that shouldn't be. So, I believe they are professional interpreters and they function as my spokespersons." -Public health nurse, Red Cross.

\section{Tactic 2: consulting WHO lists of immunization programmes worldwide}

The healthcare professionals all had access to the World Health Organization's list of immunization programmes worldwide on their computers, and could easily check each country's immunization program, thereby determining what the child should have received according to his/ her age, and what vaccinations the child would be lacking and would therefore need to receive in Denmark.

"We use it a lot! I have saved it in my favorites. I use it all the time. It is really useful, what would I do without it?" -Public health nurse, Red Cross.

One doctor said that he also used information from outbreak reports to learn more about specific vaccination needs. For example, if there had been an outbreak of polio in Syria, he expressed that he would be more observant and vaccinate the children arriving in Denmark against polio.

"If there is a five year old child coming from Syria, then I can go into the Syrian vaccination program that I will find on the WHO list, and then I can assess what the child is supposed to have had and match it with the Danish vaccination program. It makes it much easier from this point on."-Doctor, Red Cross.

\section{Tactic 3: drawing on tacit knowledge about country vaccination programmes}

Two of the other doctors and public health nurses said that their assessment would depend on where the children came from and their family situation. One doctor added that children from some countries were almost never vaccinated, while others were well vaccinated.

"It also depends on where they come from. Syrian children are normally very well vaccinated for example. And then it also depends a bit on how they act here with me. Like, how long have they been travelling, and why have they chosen to flee and seek asylum in Denmark. - We cannot do more than ask them!" -Doctor, Red Cross.

\section{Tactic 4: considering the background of parents}

One public health nurse said that she had the impression that educational status and vaccination needs were linked, assuming that if the caretakers were well educated, the chances that the child would be vaccinated before coming to Denmark and not require further vaccinations were higher. Another nurse expressed the opinion that it also depended on geographical variations within the countries and hierarchical position. For example, if the family lived in a rural area and had little access to health services, or if they were considered entitled or not to receive healthcare in their country, that might affect whether or not they had received vaccinations prior to leaving their country of origin.

"I think it relates to how well educated the people from the area they come from are. I think it is linked, the education status of their population and their vaccination status. I think it's related." -Public health nurse, Red Cross.

Tactic 5: err on the side of caution and revaccinate If the children were unaccompanied and the vaccination needs difficult to determine, the doctors stated that they 
would almost always start to revaccinate, to ensure that the child would be 'covered'. One doctor said that in his experience, doctors handled these situations differently. Some preferred to start vaccinating from the beginning again, while others preferred to give a booster vaccine, depending on the child's age. Another doctor also expressed that the decisions regarding what to do in these cases were based on each doctors' individual assessment and experience. According to one doctor's statement, all unaccompanied children who were coming were at least 15 years old, and would therefore know a little bit about their own vaccination situation, which made it easier.

"(...) But the unaccompanied that come, they are 15 years old minimum. I haven't met someone who is younger than that. So they normally know something about it, and if they don't then they receive a booster."Doctor, Red Cross.

Another doctor stated that he thought the unaccompanied minors were the most difficult to assess, as they almost never remembered their vaccination status, regardless of age, and even if they did remember being vaccinated, they did not know which ones.

"I would say that the unaccompanied minors can be difficult. Also because I'm a bit careful starting up from the beginning with them, I know that they probably have had some boosters in other countries. Now, it's not particularly dangerous to give them one more, but one can easily over-give and give them lots of vaccines that they might have had already. So I think they are difficult, because they can almost never remember if they have received anything at all." Doctor, Red Cross.

In the absence of asylum-seekers bringing with them some sort of vaccination documentation, the healthcare providers generally agreed that these tactics worked reasonably well, but also felt that they could be more disciplined and better at investigating the children's immunization status. One doctor stipulated that current tactics probably resulted in many children getting 'overvaccinated'.

"Well, I'm not in doubt that one could be better disciplined and investigate more thoroughly. But now it is like this, and so they just get boosters, maybe even if my gut feeling tells me that they are actually finished with their vaccinations. Personally, I think that might be a kind of 'overkill' in a way. But I have the impression that it works quite well, and that there aren't many who 'slip through' and are not vaccinated at the asylum centers." -Doctor, Red Cross.

\section{Discussion}

We set out to explore the tactics employed by healthcare providers in Denmark to ascertain the vaccination needs of asylum-seeking children. The first tactic pertained to obtaining documentation of previous vaccinations. However, more often than not, this was not available, instigating a whole range of tactics, including asking into their vaccination history through the use of qualified interpreters; consulting WHO lists of immunization programmes worldwide; drawing on tacit knowledge about country vaccination programmes; considering the background of parents; err on the side of caution and revaccinate. These practices demonstrate the efforts made by healthcare providers to try and do what they see as right within the limited time and resources they have at their disposal: 1) develop a full picture of children's vaccination history; and 2) revaccinate in situations of uncertainty.

The lack of immunization documentation has been shown to be an important influence on the immunization assessments of healthcare professionals' in other contexts [8, 16-18]. Paxton et al.'s [8] study found that parent-reported vaccination status did not predict serological immunity, indicating that the legitimacy of the information provided is questionable. Similarly, another study found that in depending on statements given by families, healthcare professionals did not feel completely certain of the legitimacy of the information given which made the assessments of vaccination status of refugee children more complex [19]. Additionally, some have argued that knowledge held by healthcare providers regarding a child's immunization status did not predict with certainty the vaccination status of the child, and advocate for the need of formal documentation as the secure way of determining a child's immunization status [19]. In this study we found that in cases of uncertainty regarding the information provided, administering boosters was considered the preferred, low-risk solution of healthcare providers. However, others propose serology testing in cases of doubt as the favored solution [19]. Although the findings in this study point to booster vaccines as the preferred option among healthcare staff, there are numerous studies that have found a correlation between the overly frequent administration of certain vaccines and increased risks of negative reactions $[18,20]$, which brings this practice as the most desirable option into question. Others have discussed the cost and practicality of serology testing where findings suggest that the cost-effectiveness and practice of serology testing is debatable [18]. Poethko-Müller et al. [21] found that healthcare staff may overestimate vaccination coverage in cases where formal documentation is not available. 
An interesting addition to this debate is Chai et al.'s [16] study, which found that although there was a risk of overestimating vaccination needs because of lost documentation among healthcare professionals, the percentage of missing vaccinations among refugee children was similar to that of children who remained in Ethiopia -the country of origin of the majority of the population investigated in their study. Their discovery indicates that pre-migration factors in the children's country of origin are superior in determining immunization outcomes than post-migration factors, as exemplified by the tendency of healthcare professionals in the receiving country to overestimate vaccination coverage in the event of a lack of formal documentation.

Our findings are constrained by some methodological limitations, which deserve mentioning. First, the study relies on self-reported data and it is difficult for us to ascertain what happens in clinical practice. Future research in this area of study may consider adopting an ethnographic approach Second, and relatedly, the participants were all recruited through a gatekeeper and represent an international relief organization whose reputation they may feel obliged to protect. As such, our study was susceptible to social desirability bias, such as participants representing themselves as following official Red Cross policies. CN only noted a few instances where participants appeared cautious about sharing their perspectives. Third, our study was cross-sectional and only provides a brief snapshot (during the peak of the migration flow to Denmark) into healthcare providers' strategies for determining the vaccination needs of asylum-seeking children at a particular moment in time. Longitudinal research, unpacking the dynamic and changing nature of their tactics would be useful. Fourth, the generalizability of our findings is limited and may not apply to other settings, as the structure and delivery of health services for asylum-seeking children in our setting may well vary from others. This study only explored the perspectives of healthcare providers. Future research could usefully broaden its scope and include the perspectives and experiences of refugee families.

\section{Conclusions}

This is one of the first studies to demonstrate the tactics employed by healthcare providers to ascertain the immunization needs of asylum-seeking children in a western receiving country. The study uncovers several areas in need of attention. First, health care providers appear to need more information and clear guidance to help them determine the vaccination status of asylum-seeking children and to reach a more homogenous and systematic assessment amongst providers. The Danish Red Cross has some internal guidelines but no guidelines exist from the National Board of health on this issue. This is further complicated by the fact that asylum seekers may be promptly resettled in one out of the 98 municipalities in Denmark, or in asylum centers run by local municipalities. Studies show that municipalities have very diverse and often inadequate services regarding the health reception of refugee families [22]. Second, our study expands on the importance of healthcare professionals having accurate information and immunization documentation to determine vaccination status and needs. The contradicting arguments presented in this article indicate that the information available for clinical decision-making is not optimal, and highlights the need for joint and international efforts to secure reliable immunization documentation for migrant populations. Improved recordkeeping would contribute to a decrease in the incidence of over-vaccination without adversely affecting immunity. WHO encourage governments to provide caregivers with documentation of the vaccines given to avoid unnecessary vaccination. Even if this practice was widespread, the circumstances forcing people to flee their home countries and seek asylum in another country, makes reliance on a paper-based immunization documentation system untenable. In light of our increasingly globalized world and digital age, perhaps we should begin to consider virtual immunization records?

\section{Abbreviations}

WHO: World Health Organization

\section{Acknowledgements}

We would like to thank the Danish Red Cross Asylum Department for their time and efforts. We appreciate the support and collaboration from the Danish Red Cross, especially chief medical consultant Ebbe Munk Andersen and co-director Svend Erik Brande.

Funding

This work did not receive any funding.

Availability of data and materials

The qualitative data generated and analysed for the current study are not publicly available but are available from $\mathrm{CN}$ on reasonable request.

Authors' contributions

MN designed and supervised the study. CN executed the study, conducting the interviews. CN analysed data in conversation with MS and MN. MS and $\mathrm{CN}$ wrote the first draft of the paper, and all authors read and approved the final manuscript.

Ethics approval and consent to participate

According to Danish law, only studies gathering human tissue need approval from an ethics committee. Permission to conduct the study was granted by the Danish Data Protection Agency. All participants received written information about the study prior to giving consent. Informed and written consent was obtained from all participants upon the agreement that their identities would be revealed, and that they could withdraw from participation at any time.

Consent for publication

Not applicable.

Competing interests

The authors declare that they have no competing interests. 


\section{Publisher's Note}

Springer Nature remains neutral with regard to jurisdictional claims in published maps and institutional affiliations.

\section{Author details}

'Danish Research Center for Migration, Ethnicity and Health, Section for Health Services, Research, Department of Public Health, University of Copenhagen, Øster Farimagsgade 5, 1353 København K, Denmark. ${ }^{2}$ Section of Immigrant Medicine, Department of Infectious Diseases, Copenhagen University Hospital, Hvidovre Hospital, Hvidovre, Denmark.

Received: 13 March 2018 Accepted: 29 October 2018

Published online: 14 November 2018

\section{References}

1. European Commission: Compilation of data, situation and media reports on children in migration. 2017. http://ec.europa.eu/justice/fundamental-rights/ files/rights_child/data_children_in_migration.pdf. Accessed 12 Jan 2018.

2. Udlændingestyrelsen: Tal og fakta på udlændingeområdet 2016: Udlændingestyrelsen. 2017. https://www.nyidanmark.dk/da/Tal-ogstatistik/Tal-og-fakta. Accessed 12 Jan 2018.

3. WHO. WHO-UNHCR-UNICEF joint technical guidance: general principles of vaccination of refugees, asylum-seekers and migrants in the WHO European Region. World Health Organisation; 2015. http://www.euro.who.int/en/ health-topics/communicable-diseases/poliomyelitis/news/news/2015/11/ who,-unicef-and-unhcr-call-for-equitable-access-to-vaccines-for-refugeesand-migrants/who-unhcr-unicef-joint-technical-guidance-general-principlesof-vaccination-of-refugees,-asylum-seekers-and-migrants-in-the-whoeuropean-region. Accessed 15 Jan 2018.

4. De Vito E, Parente P, de Waure C, Poscia A, Ricciardi W. A review of evidence on equitable delivery, access and utilization of immunization services for migrants and refugees in the WHO European region. Copenhagen: WHO Regional Office for Europe (Health Evidence Network (HEN) synthesis report 53); 2017.

5. National Board of Health: Børnevaccinationsprogrammet i Danmark. 2016. https://sundhedsstyrelsen.dk/da/sygdom-og-behandling/ /media/ 811A9F6CD64B4462B6FDFE503787CC71.ashx. Accessed 24 Feb 2016.

6. Jablonka A, Happle C, Grote U, Schleenvoigt BT, Hampel A, Dopfer C, Hansen G, Schmidt RE, Behrens GM. Measles, mumps, rubella, and varicella seroprevalence in refugees in Germany in 2015. Infection. 2016;44(6):781-7.

7. Riccardo F, Dente MG, Kärki T, Fabiani M, Napoli C, Chiarenza A, Rossi PG, Munoz CV, Noori T, Declich S. Towards a European framework to monitor infectious diseases among migrant populations: design and applicability. Int J Environ Res Public Health. 2015;12(9):11640-61.

8. Paxton GA, Rice J, Davie G, Carapetis JR, Skull SA. East African immigrant children in Australia have poor immunisation coverage. J Paediatr Child Health. 2011:47(12):888-92.

9. De Certeau M. The practice of everyday life (S. Rendall, Trans.). Berkeley: University of California Press; 1984.

10. Danish Immigration Service: Hvor ligger centrene? 2017. https://www. nyidanmark.dk/da/Ord-og-begreber/US/Indkvartering/Asylcentre. Accessed 2 Mar 2017.

11. Mulrow CD, Cook DJ, Davidoff F. Systematic reviews: critical links in the great chain of evidence. Ann Intern Med. 1997;126(5):389-91.

12. Ozbolt JG. Personalized health care and business success: can informatics bring us to the promised land? J Am Med Inform Assoc. 1999;6(5):368-73.

13. Skovdal M, Cornish F. Qualitative research for development: a guide for practitioners. Rugby: Practical Action Publishing; 2015.

14. Attride-Stirling J. Thematic networks: an analytic tool for qualitative research. Qual Res. 2001;1(3):385-405.

15. Nakken CS, Skovdal M, Nellums LB, Friedland JS, Hargreaves S, Norredam MJP. Vaccination status and needs of asylum-seeking children in Denmark: a retrospective data analysis. Public Health. 2018;158:110-6.

16. Chai SJ, Davies-Cole J, Cookson ST. Infectious disease burden and vaccination needs among asylees versus refugees, District of Columbia. Clin Infect Dis. 2012;56(5):652-8.

17. Watts D-J, Friedman JF, Vivier PM, Tompkins CE, Alario AJ. Immunization status of refugee children after resettlement. Med Health Rhode Island. 2011;94(10):290.

18. Barnett E. Immunizations for Immigrants. In: Walker P, Barnett $E$, editors. Immigrant medicine. Philadelphia: Saunders Elsevier; 2007. p. 151-70.
19. de Monléon J-V, Regnier F, Ajana F, Baptiste C, Callamand P, Cheymol J, Gillet $Y$, Hau-Rainsard I, Lorrot M, Reinert P. Mise à jour des vaccinations de l'enfant arrivant de l'étranger (adopté, réfugié ou migrant) en France. Arch Pediatr. 2014;21(3):329-34.

20. Atkinson WL, Pickering LK, Schwartz B, Weniger BG, Iskander JK, Watson JC. General recommendations on immunization. Recommendations of the Advisory Committee on Immunization Practices (ACIP) and the American Academy of Family Physicians (AAFP). MMWR Recomm Rep. 2002;51:1-35.

21. Poethko-Müller C, Ellert U, Kuhnert R, Neuhauser H, Schlaud M, Schenk L. Vaccination coverage against measles in German-born and foreign-born children and identification of unvaccinated subgroups in Germany. Vaccine. 2009;27(19):2563-9.

22. Frederiksen HW, Krasnik A, Norredam M. Policies and practices in the healthrelated reception of quota refugees in Denmark. Dan Med J. 2012;59(1):A4352.

\section{Ready to submit your research? Choose BMC and benefit from:}

- fast, convenient online submission

- thorough peer review by experienced researchers in your field

- rapid publication on acceptance

- support for research data, including large and complex data types

- gold Open Access which fosters wider collaboration and increased citations

- maximum visibility for your research: over $100 \mathrm{M}$ website views per year

At BMC, research is always in progress.

Learn more biomedcentral.com/submissions 